\title{
Mice Expressing Myc in Neural Precursors Develop Choroid Plexus and Ciliary Body Tumors
}

Morgan L. Shannon, ${ }^{*}$ Ryann M. Fame, ${ }^{*}$ Kevin F. Chau, ${ }^{*}$ Neil Dani, ${ }^{*}$ Monica L. Calicchio, ${ }^{*}$ Gwenaelle S. Géléoc, ${ }^{\delta \oplus}$ Hart G.W. Lidov, ${ }^{*}$ Sanda Alexandrescu, ${ }^{*}$ and Maria K. Lehtinen ${ }^{* \ddagger}$

From the Departments of Pathology* and Otolaryngology ${ }^{\S}$ and the F.M. Kirby Center for Neurobiology, "Boston Children's Hospital, Boston; and the Program in Biological and Biomedical Sciences, ${ }^{\ddagger}$ Harvard Medical School, Boston, Massachusetts

Accepted for publication

February 20, 2018.

Address correspondence to Maria K. Lehtinen, Ph.D., Department of Pathology, Boston Children's Hospital, 300 Longwood Ave., Boston, MA 02115. E-mail: maria.lehtinen@ childrens.harvard.edu.

\begin{abstract}
Choroid plexus tumors and ciliary body medulloepithelioma are predominantly pediatric neoplasms. Progress in understanding the pathogenesis of these tumors has been hindered by their rarity and lack of models that faithfully recapitulate the disease. Here, we find that endogenous Myc proto-oncogene protein is down-regulated in the forebrain neuroepithelium, whose neural plate border domains give rise to the anterior choroid plexus and ciliary body. To uncover the consequences of persistent Myc expression, MYC expression was forced in multipotent neural precursors (nestin-Cre:Myc), which produced fully penetrant models of choroid plexus carcinoma and ciliary body medulloepithelioma. Nestin-mediated MYC expression in the epithelial cells of choroid plexus leads to the regionalized formation of choroid plexus carcinoma in the posterior domain of the lateral ventricle choroid plexus and the fourth ventricle choroid plexus that is accompanied by loss of multiple cilia, up-regulation of protein biosynthetic machinery, and hydrocephalus. Parallel MYC expression in the ciliary body leads also to up-regulation of protein biosynthetic machinery. Additionally, Myc expression in human choroid plexus tumors increases with aggressiveness of disease. Collectively, our findings expose a select vulnerability of the neuroepithelial lineage to postnatal tumorigenesis and provide a new mouse model for investigating the pathogenesis of these rare pediatric neoplasms. (Am J Pathol 2018, 188: 1334-1344; https://doi.org/10.1016/j.ajpath.2018.02.009)
\end{abstract}

Choroid plexus neoplasms [choroid plexus papilloma and choroid plexus carcinoma (CPC)] and ocular ciliary body medulloepithelioma (CBME) represent rare tumors of early childhood, with median ages of onset of $3.5^{1}$ and 5 years, respectively. Surgical resection remains the only effective therapy for these tumors, but they can recur and metastasize, with devastating consequences. Recent work suggests that epigenetic dysregulation, TP53 mutations with Li-Fraumeni syndrome, and several genetic mutations can lead to choroid plexus neoplasms. ${ }^{1,3-6}$ However, the molecular pathogenesis of these tumors remains poorly understood. Critically, even less is known regarding CBME, for which no mouse models currently exist.

Pediatric tumors often harken back to missteps during development. Progress has been made in understanding the molecular mechanisms for more common pediatric tumors, including medulloblastoma, for which tumor geneexpression profiles from relevant progenitors inform therapy choice and prognosis. ${ }^{7-9}$ During normal development, Myc family members are highly expressed in embryonic tissues, but not in adult tissues. ${ }^{10}$ Forced persistent expression of $\mathrm{N}$-myc in neural stem cells gives rise to various tumors, including medulloblastoma/primitive neuroectodermal tumors and diffuse glioma. ${ }^{11}$ We focused on the expression of a different Myc subtype, c-Myc (Myc hereafter), in forebrain neuroepithelial progenitors. These progenitors extend to the anterior neural plate border and

Supported by a National Science Foundation Graduate Research Fellowship (K.F.C.); NIH grant T32 HL110852 (K.F.C. and R.M.F.); the William Randolph Hearst Fund (N.D.); the Pediatric Hydrocephalus Foundation, NIH grant R01 NS088566, and the New York Stem Cell Foundation (M.K.L.); and Boston Children's Hospital Intellectual and Developmental Disabilities Research Center (BCH IDDRC 1U54HD090255). M.K.L. is a New York Stem Cell Foundation-Robertson Investigator.

M.L.S., R.M.F., and K.F.C. contributed equally to this work.

Disclosures: None declared. 
Table 1 Histologic and Immunohistochemical Characterization of Choroid Plexus Tumors

\begin{tabular}{|c|c|c|c|c|c|c|c|}
\hline Identifier & $\begin{array}{l}\text { Mitoses } \\
\text { per } 10 \text { HPF }(\times 60)\end{array}$ & $\begin{array}{l}\text { Increased } \\
\text { cellular density }\end{array}$ & $\begin{array}{l}\text { Nuclear } \\
\text { pleomorphism }\end{array}$ & $\begin{array}{l}\text { Loss of } \\
\text { papillary } \\
\text { architecture }\end{array}$ & Necrosis & $\begin{array}{l}\text { TTR } \\
\text { immunoreactivity }\end{array}$ & $\begin{array}{l}\text { Kir7.1 } \\
\text { immunoreactivity }\end{array}$ \\
\hline Мyc-0E $14 \mathrm{~V} \mathrm{CPC}$ & 6 & + & + & + & - & + & + \\
\hline Myc-0E 2 LV CPC & 7 & + & + & + & - & + & + \\
\hline Мyc-0E $24 \mathrm{~V} \mathrm{CPC}$ & 17 & + & + & + & - & + & + \\
\hline
\end{tabular}

$4 \mathrm{~V}$, fourth ventricle; CPC, choroid plexus carcinoma; HPF, high-power fields; Kir7.1, anti-Inward rectifier $\mathrm{K}^{+}$channel Kir7.1; LV, lateral ventricle; 0E, overexpressed; TTR, transthyretin.

give rise to both the anterior choroid plexus and ciliary body of the eye. ${ }^{12,13}$ Endogenous Myc expression was down-regulated in the developing forebrain neuroepithelium during neural tube closure. To test the consequences of persistent Myc expression, Myc expression was genetically induced in nestin-expressing neural precursors immediately after neural tube closure, and a mouse that acquires postnatal CPC and CBME, with complete penetrance, was generated. Examination of human choroid plexus papilloma and CPC cases indicated that increased MYC expression correlated with increased aggressiveness of disease. Our work emphasizes the prominence of regional and temporal restrictions in tumor formation and provides a new platform for investigating the pathogenesis of these rare tumors.

\section{Materials and Methods}

\section{Study Approval}

All animal experimentation was performed using protocols approved by the Institutional Animal Care and Use Committee of Boston Children's Hospital (Boston, MA). All human samples were obtained using an IRB-approved protocol at Boston Children's Hospital.

\section{Mice}

StopFLMYC mice (catalog number 020458; The Jackson Laboratory, Bar Harbor, ME) were maintained in a C57BL/ $6 \mathrm{~J}$ genetic background and crossed with nestin-Cre (catalog number 003771; The Jackson Laboratory) to generate Myc-overexpressed (OE) mice, in which human MYC transgene is expressed in neural progenitor cells. Please refer to Table 1 for histologic and immunohistochemical characterization of choroid plexus tumors in nestin-Credriven Myc-OE mice. Rosa ${ }^{\mathrm{mTmG}}$ (catalog number 007676; The Jackson Laboratory) was crossed with nestin-Cre (catalog number 003771; The Jackson Laboratory) to generate nestin-Cre/Rosa ${ }^{\mathrm{mTmG}}$ reporter mice. All analyses were performed using both male and female mice.

\section{Human Samples}

Table 2 lists information on the ages and sexes of the human choroid plexus samples used. Any tumor sample with a mean percentage of Myc-expressing cells of 5\% or higher was defined as $M y c$-positive, and any sample with a mean percentage of Myc-expressing cells under 5\%, as Mycnegative.

\section{Nucleolar Volume Quantification}

Nucleolar volume was quantified in accordance with published methods. ${ }^{14,15}$ Cryosections for quantification were $20 \mu \mathrm{m}$ thick and stained with anti-fibrillarin antibody (Abcam, Cambridge, MA). Z-stack images were acquired using the $\times 40$ objective on an LSM 700 laser scanning confocal microscope (Carl Zeiss, Oberkochen, Germany). Three-dimensional reconstruction was performed using the Surface tool in Imaris image analysis software version 7.7.1 (Bitplane, Zurich, Switzerland). Nucleoli with sphericity $<0.44$ or volume $<0.10 \mu \mathrm{m}^{3}$ were considered as staining artefacts and excluded. Nucleolar volume was quantified using Imaris in a blinded manner (M.L.S., R.M.F., and K.F.C.).

\section{Choroid Plexus 0-Propargyl-Puromycin Incorporation}

Fresh choroid plexuses were dissected into Dulbecco's modified Eagle's media and incubated at $37^{\circ} \mathrm{C}$ for $30 \mathrm{mi}-$ nutes in neurobasal medium with $1 \%$ penicillin/streptomycin and $1 \%$ GlutaMAX (Thermo Fisher Scientific, Waltham, MA). After 30 minutes of incubation with 20 $\mu \mathrm{mol} / \mathrm{L}$ O-propargyl-puromycin in neurobasal medium with $1 \%$ penicillin/streptomycin and $1 \%$ GlutaMAX, choroid plexuses were briefly washed with sterile phosphatebuffered saline, fixed for 15 minutes in $4 \%$ paraformaldehyde, and cryoprotected in 30\% sucrose. Samples were frozen in optimal cutting temperature compound (Thermo Fisher Scientific) and cryosectioned to a thickness of $7 \mu \mathrm{m}$. O-propargyl-puromycin signals were detected using the Click-iT plus O-propargyl-puromycin protein 
Table 2 Information on Human Choroid Plexus Samples Used in This Study

\begin{tabular}{|c|c|c|c|c|}
\hline Identifier & Sex & Age & Diagnosis & Location \\
\hline CP_A & $\mathrm{F}$ & $10 \mathrm{y}$ & $\begin{array}{l}\text { T-cell acute lymphoblastic } \\
\text { leukemia, hemorrhagic bronchopneumonia, } \\
\text { organizing interstitial pneumonitic and acute } \\
\text { respiratory distress syndrome in the setting of } \\
\text { possible sepsis and underlying myelodysplastic } \\
\text { syndrome }\end{array}$ & Temporal lobe \\
\hline CP_B & $\mathrm{F}$ & $5 \mathrm{mo}$ & Suspected bilateral cerebral infarcts & Temporal lobe \\
\hline CP_C & $\mathrm{F}$ & $12 \mathrm{mo}$ & Persistent vegetative state & Temporal lobe \\
\hline CP_D & $\mathrm{F}$ & 15 y & Cystic fibrosis & Temporal lobe \\
\hline CPP_a & M & $8 \mathrm{mo}$ & CPP & Infratentorial \\
\hline CPP_b & M & $10 \mathrm{y}$ & CPP & Fourth ventricle, posterior fossa \\
\hline CPP_C & M & $4 \mathrm{mo}$ & CPP & Left ventricle \\
\hline CPP_d & M & $2 y$ & CPP & Right ventricle \\
\hline CPP_e & M & $1 \mathrm{y}$ & CPP & Left ventricle \\
\hline CPP_f & M & $7 \mathrm{y}$ & CPP & Fourth ventricle \\
\hline CPP_g & $\mathrm{F}$ & $16 \mathrm{y}$ & CPP & Fourth ventricle, posterior fossa \\
\hline CPP_h & M & $20 \mathrm{y}$ & CPP & Posterior fossa \\
\hline CPC_a & M & $6 y$ & CPC & Left parietal and temporal lobes \\
\hline CPC_b & $\mathrm{F}$ & $1 \mathrm{y}$ & CPC & Left ventricle \\
\hline CPC_C & M & $11 \mathrm{y}$ & CPC & Left temporal lobe \\
\hline CPC_d & $\mathrm{F}$ & $5 y$ & CPC & Left ventricle, cerebral cortex \\
\hline CPC_e & M & $2 y$ & CPC & $\begin{array}{l}\text { Posterior lateral wall, anterior medial wall, } \\
\text { posterior and lateral tissue }\end{array}$ \\
\hline$C P C \_f$ & M & $1 \mathrm{y}$ & CPC & Not Specified \\
\hline CPC_g & M & $14 \mathrm{y}$ & CPC & Fourth ventricle, suboccipital \\
\hline
\end{tabular}

F, female; M, male; CPC, choroid plexus carcinoma; CPP, choroid plexus papilloma.

synthesis assay kit (Thermo Fisher Scientific) according to the manufacturer's suggested procedures. Images were acquired at $\times 10$ using a Nikon Eclipse inverted microscope (Nikon Instruments, Melville, NY), and fluorescence intensity was quantified using ImageJ software version 2.0.0rc-43/1.51g (NIH, Bethesda, MD; http://imagej.nih.gov.ij). In ImageJ, the Hoechst-stained layer was used to create an unbiased mask of individual, nonoverlapping cells. To crease the mask, the Hoechst-stained layer was subjected to an unsharp mask $(\Sigma=4.0, \mathrm{w}=0.6)$, then thresholded using the automatic Otsu thresholding protocol. This thresholded image was subjected to the watershed protocol and then used to create the mask. This mask was applied to the original image, and particles between 25 and 250 pixels in size were analyzed for fluorescence intensity in the green O-propargyl-puromycin channel. All values of raw intensity density under 1000 intensity units were excluded as background. Individual values from choroid plexus cells were then analyzed for a change in overall distribution of gray levels using the Mann-Whitney $U$-test.

\section{Tissue Fixation and Processing}

Dissected choroid plexuses and eyes were fixed in $4 \%$ paraformaldehyde (in $1 \times$ phosphate-buffered saline, $\mathrm{pH} 7.4$ ). Pups and adults were transcardially perfused, and brains were dissected for postfixation in $4 \%$ paraformaldehyde. For microtome sectioning, samples were embedded in paraffin. For cryosectioning, samples were incubated in the following series of solutions in $1 \times$ phosphate-buffered saline: $10 \%$ sucrose, $20 \%$ sucrose, $30 \%$ sucrose, 1:1 mixture of $30 \%$ sucrose and optimal cutting temperature compound (overnight), and optimal cutting temperature compound (1 hour). Samples were frozen in optimal cutting temperature compound.

\section{Immunohistochemical Analysis}

Cryosections were blocked and permeabilized (0.3\% Triton $\mathrm{X}-100$ in phosphate-buffered saline, $5 \%$ serum), incubated in primary antibodies overnight, and then in secondary antibodies for 2 hours. Sections were counterstained with Hoechst 33342 (Thermo Fisher Scientific) and mounted using Fluoromount-G (SouthernBiotech, Birmingham, AL). Paraffin-embedded sections were deparaffinized and stained on Bond stainer (Leica Microsystems). The following primary antibodies were used: anti-ADP-ribosylation factorlike protein 13b (Arl13b; 1:500; catalog number 17,711-1AP; Proteintech, Rosemont, IL), anti-mCherry (1:500; catalog number ab167453; Abcam), anti-cone-rod homeobox [CRX; kindly gifted by Dr. Sandro Santagata (Brigham and Women's Hospital, Boston, MA)], anti-fibrillarin (1:250; catalog number ab4566; Abcam), anti-green fluorescent protein (GFP; 1:1000; catalog number ab13970; Abcam), anti-human melanoma black (HMB)-45 (prediluted; catalog number 282M-98; Cell Marque, Rocklin, CA), anti-Ki-67 (SP6; prediluted; catalog number 275R-18; Cell Marque), 
A

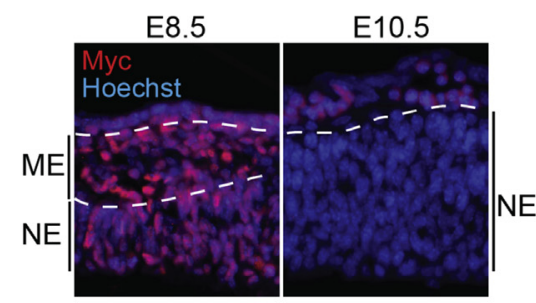

B

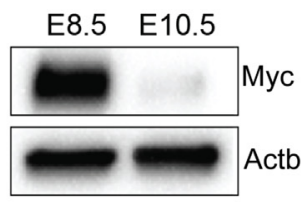

C

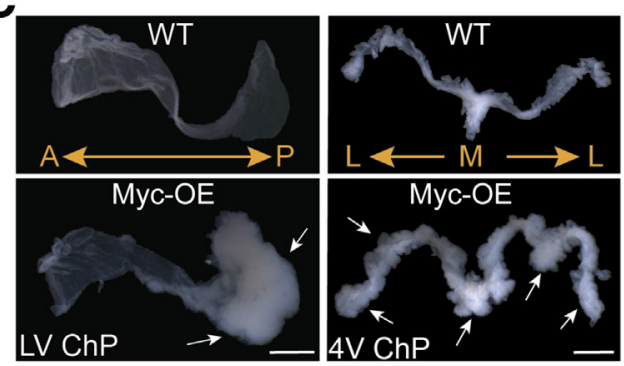

D

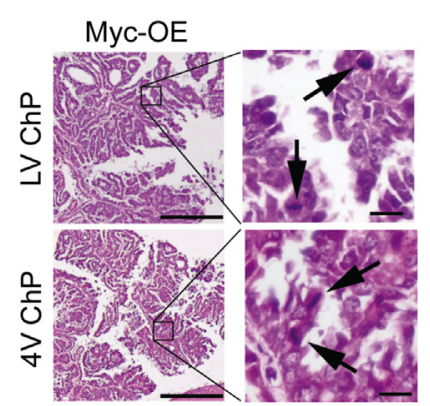

E

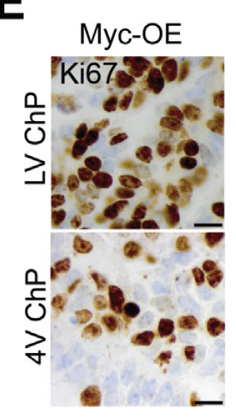

$\mathbf{F}$

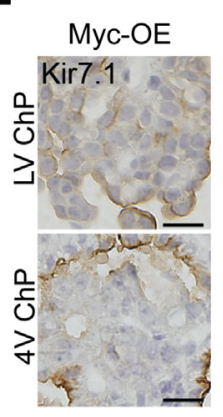

G

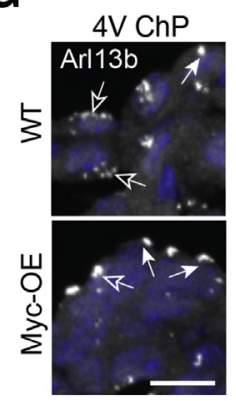

$\mathrm{H}$

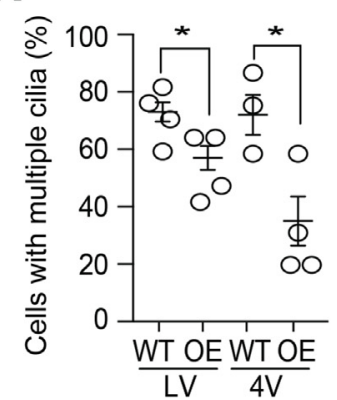

Figure 1 Persistent Myc expression drives tumorigenesis in choroid plexus (ChP). A and B: Immunohistochemical (A) and immunoblot analyses (B) demonstrate higher Myc expression in embryonic day (E) 8.5 forebrain compared to E10.5 forebrain. Dashed lines indicate division between surface ectoderm, mesenchyme (ME), and neuroepithelium (NE) at E8.5, and division between the developing epidermis/meninges and the neuroepithelium at E10.5. C: Lateral ventricle (LV) and fourth ventricle (4V) choroid plexuses from 8- to 9-week-old wild-type (WT) and Myc-overexpressed (OE) mice. White arrows denote tumorigenic region. Note posterior regionalization of tumor in the LV choroid plexus, whereas tumor develops throughout the $4 \mathrm{~V}$ choroid plexus. D: Hematoxylin and eosin staining shows choroid plexus carcinoma in the LV and $4 \mathrm{~V}$ choroid plexuses of Myc- $0 \mathrm{E}$ mice. Arrows indicate mitoses; the boxed areas in left panels are shown at higher magnification in right panels. E: Ki-67 staining shows high proliferation in choroid plexus tumors in both $\mathrm{LV}$ and $4 \mathrm{~V}$ of Myc- $0 \mathrm{E}$ mice. F: Tumors in both LV and $4 \mathrm{~V}$ are variably immunoreactive to renal inward rectifier $\mathrm{K}^{+}$channel (Kir7.1). $\mathbf{G}$ and $\mathbf{H}$ : The percentage of multiciliated epithelial cells is decreased in both the LV and $4 \mathrm{~V}$ choroid plexuses in the tumorigenic regions of 8-week-old Myc-0E mice. Solid arrows indicate monociliated cells; open arrows indicate multiciliated cells. Data expressed as means \pm SEM (H). ${ }^{*} P<0.05$ (Welch corrected $t$-test). Scale bars: $1 \mathrm{~mm}$ (C); $500 \mu \mathrm{m}$ (D, left); 20 $\mu \mathrm{m}(\mathbf{D}$, right; $\mathbf{E}$ and $\mathbf{F}) ; 10 \mu \mathrm{m}(\mathbf{G})$. A, anterior; Actb, $\beta$-actin; Arl13b, ADP-ribosylation factor-like protein 13b; L, lateral; M, medial; P, posterior.

anti-Inward rectifier $\mathrm{K}^{+}$channel Kir7.1 (Kir7.1; 1:50; catalog number sc-398810; Santa Cruz Biotechnology, Dallas, TX), anti-Myc (1:100; catalog number ab32072; Abcam), anti-human Myc (1:100; catalog number ac-0116; Epitomics, Burlingame, CA), anti-S100 (prediluted; catalog number PA0900; Leica Microsystems), anti-synaptophysin (prediluted; catalog number PA0299; Leica Microsystems), and anti-transthyretin (1:100; catalog number A0002; Agilent, Santa Clara, CA). Secondary antibodies were selected from the Alexa series (1:500; Thermo Fisher Scientific). For fibrillarin, Myc, Kir7.1, and transthyretin staining, an antigen retrieval/denaturation step was included before the blocking step: A food steamer (catalog number 5712; Oster, Boca Raton, FL) was filled with water and preheated until the chamber temperature approached $100^{\circ} \mathrm{C}$; sections were immersed in boiling citric acid buffer (10 $\mathrm{mmol} / \mathrm{L}$ sodium citrate, $0.05 \%$ Tween $20, \mathrm{pH}=6$ ) and placed in the steamer for 20 minutes. Sections were cooled to room temperature.

\section{Hematoxylin and Eosin Staining}

Paraffin-embedded brains were sectioned to a thickness of $5 \mu \mathrm{m}$. Sections were deparaffinized in xylene and then rehydrated via successive incubation in $100 \%$ ethanol, 95\% ethanol, and $\mathrm{H}_{2} \mathrm{O}$.
Sections were incubated in Gill 3 hematoxylin (Sigma-Aldrich, St. Louis, MO) for 2 minutes, and a 5-second incubation in $0.5 \%$ ammonia water was used to increase the contrast of the hematoxylin stain. Sections were rinsed in $\mathrm{H}_{2} \mathrm{O}$ and incubated in $1 \%$ alcoholic eosin for 3 minutes. Finally, sections were dehydrated via successive incubation in 95\% ethanol, $100 \%$ ethanol, and xylene, and mounted using Permount (Thermo Fisher Scientific).

\section{Positron Emission Tomography/Computerized Axial Tomography}

Mice were fasted overnight and then intravenously administered a bolus of 37 megabecquerels of ${ }^{18} \mathrm{~F}$ fluorodeoxyglucose. ${ }^{18} \mathrm{~F}$ fluorodeoxyglucose activity in the syringe was monitored before and after the injection. An uptake time of 1 hour was allowed, followed by computerized axial tomography and positron emission tomography (Bruker PET/SPECT/CT scanner, Small Animal Imaging Laboratory/Bruker, Billerica, MA) under isoflurane anesthesia. Mice were kept warm throughout the procedure to reduce ${ }^{18} \mathrm{~F}$ fluorodeoxyglucose uptake in soft tissue. Images were analyzed using Amide's a Medical Image Data Examiner software version 1.0.5 (Amide; http://amide. sourceforge.net). 
A

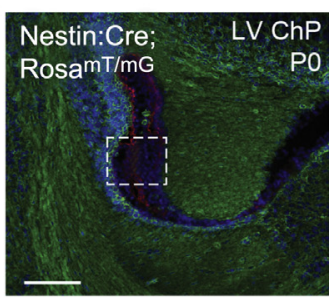

C

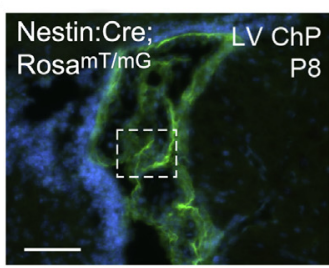

E

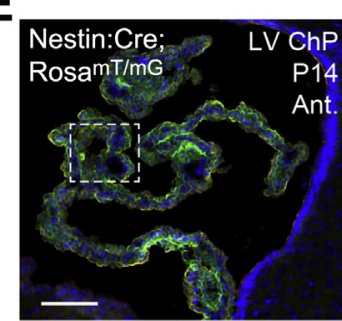

G

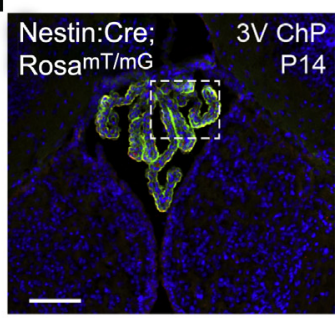

I

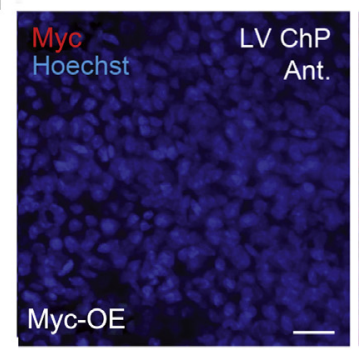

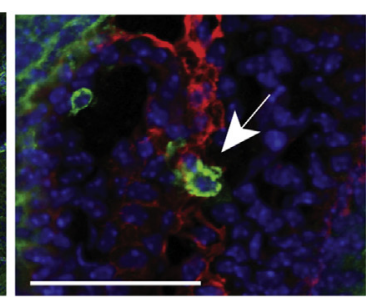
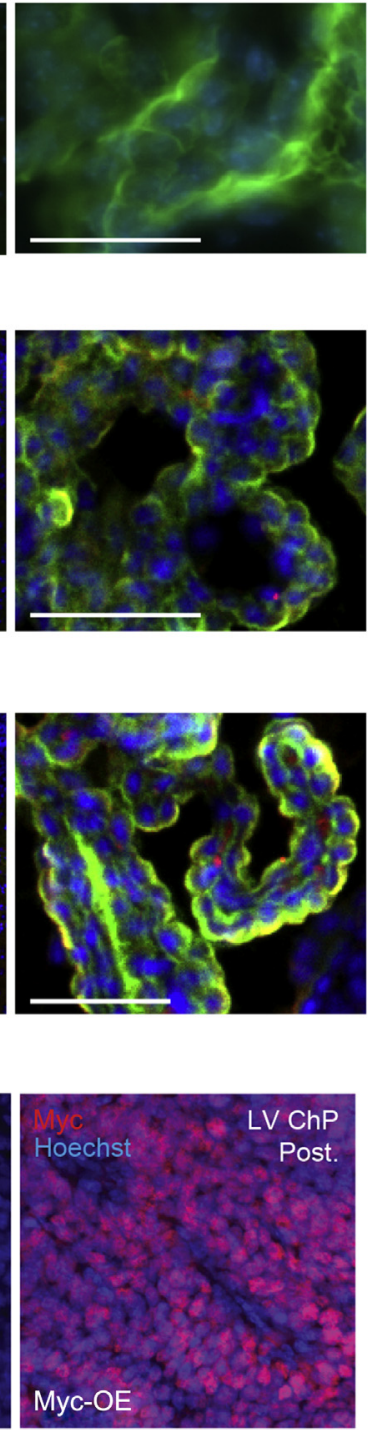

F

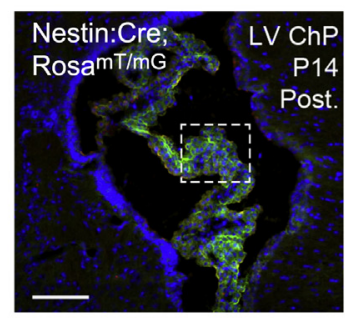

H

B
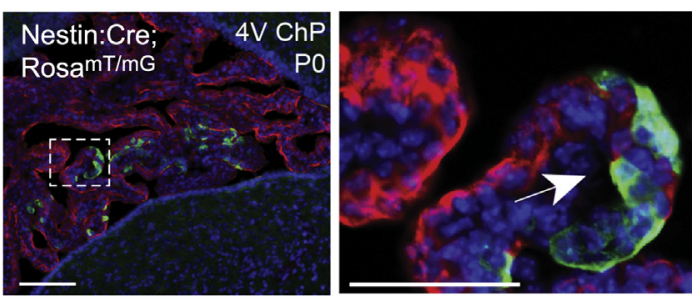

D
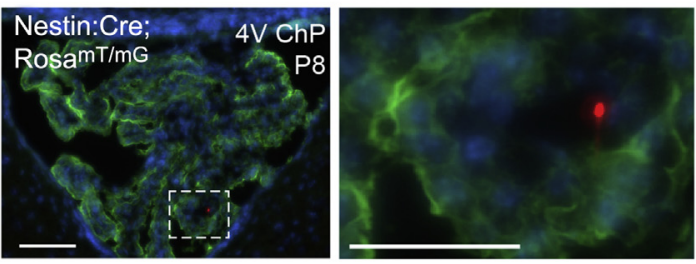

E

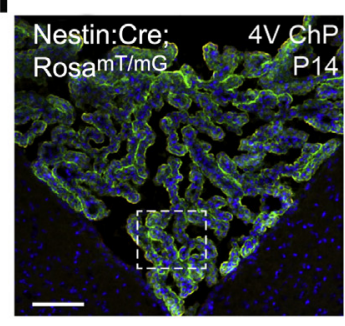

J

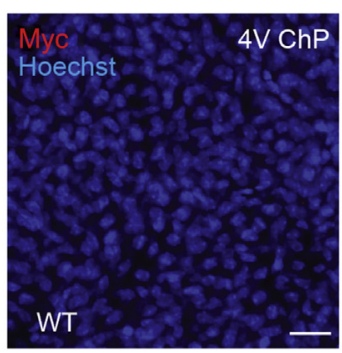

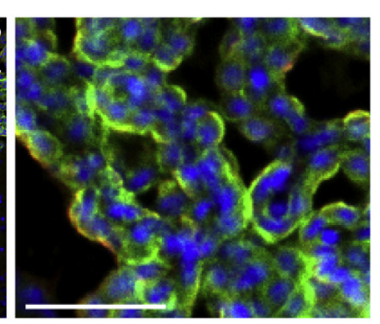
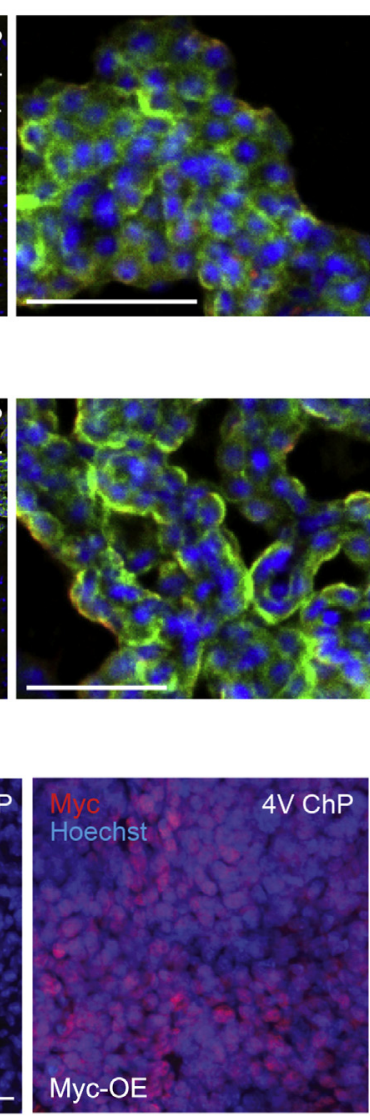

Figure 2 Nestin-Cre recombination and Myc expression in choroid plexus (ChP). A-H: Nestin-Cre recombination in lateral ventricle (LV; left) and fourth ventricle (4V; right) choroid plexuses shown by red-to-green transition in the Rosa ${ }^{\mathrm{mTmG}}$ mouse strain at postnatal day (P) 0 (A and B), P8 (C and D), and P14 $(\mathbf{E}-\mathbf{H})$. Boxed areas in left panels are shown at higher-magnification in right panels. Arrows denote recombined epithelial cells. The boxed areas in $\mathbf{A}-\mathbf{H}$ correspond to the images at the right at higher magnification. I and J: Myc-positive staining nuclei in tumorigenic regions of posterior LV (I) and $4 \mathrm{~V}$ (J) choroid plexuses of Myc-overexpressed (OE) mice. Scale bars: $100 \mu \mathrm{m}$ (A-H, left); $50 \mu \mathrm{m}(\mathbf{A}-\mathbf{H}$, right); $20 \mu \mathrm{m}$ (I and J). 3V, third ventricle; Ant., anterior; Post., posterior; WT, wild-type.

\section{Quantitative RT-PCR}

RNA was isolated using TRIzol extraction protocol or the RecoverAll Total Nucleic Acid Isolation Kit (Thermo
Fisher Scientific), and reverse-transcribed into cDNA. Gene expression was measured by TaqMan quantitative PCR (Thermo Fisher Scientific), using $T b p$ as an internal control. 


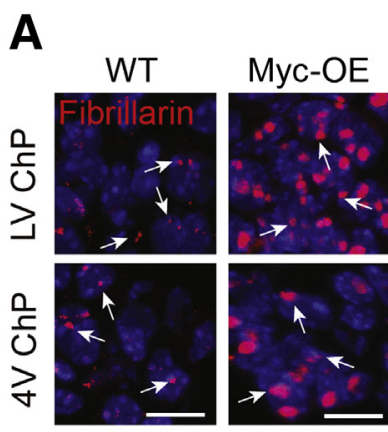

D

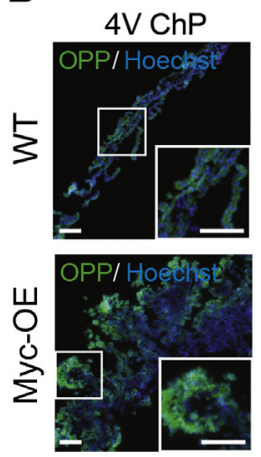

B

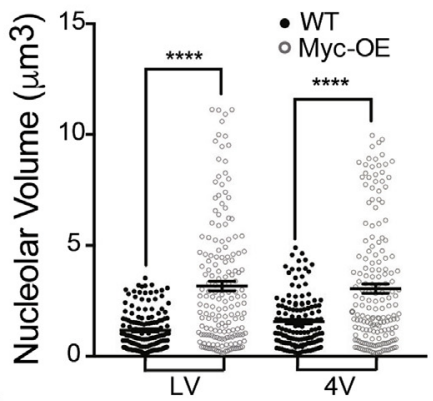

E

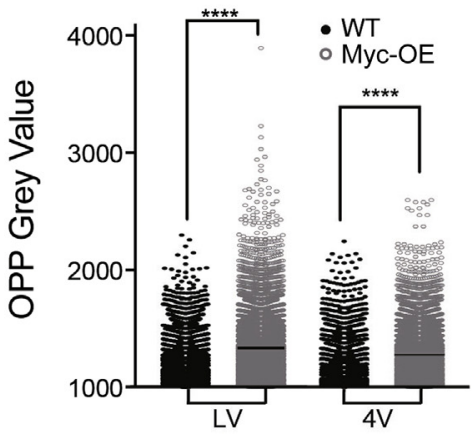

C
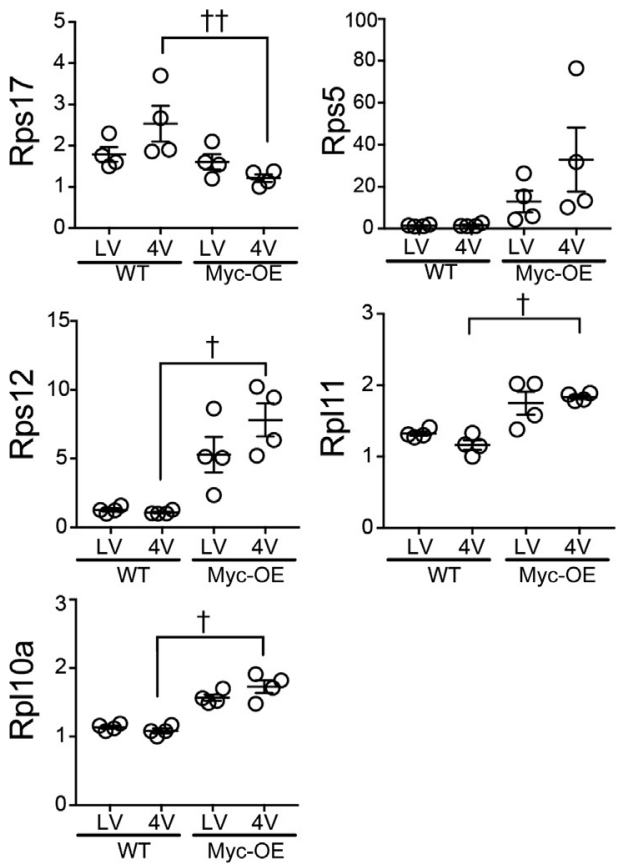

Figure 3 Myc-driven tumorigenesis up-regulates protein biosynthetic machinery. A and B: Nucleolar volume was higher in Myc-overexpressed (0E) choroid plexuses (ChP) than in those of wild-type (WT) mice at 8 weeks in both the lateral ventricle (LV) and fourth ventricle (4V). Outliers excluded by the ROUT method $(Q=1 \%)$. Arrows indicate fibrillarin-positive nucleoli. C: Quantitative RT-PCR measures changes in expression of ribosomal subunits (Rps17, Rps5, Rps12, Rpl11, and Rpl10a) in the choroid plexuses of 7- to 9-week-old Myc-0E mice. Note: LV choroid plexus samples contained entire tissue, including nontumorigenic anterior domain. D: 0-propargyl-puromycin (OPP) incorporation into WT and Myc-OE tissue. The boxed areas correspond to the insets shown at higher magnification. E: Overall distribution of cells with high protein-synthesis levels, measured by OPP incorporation, was redistributed to higher OPP levels in Myc-OE choroid plexuses than in those of WT mice at 8 weeks in both the LV and $4 \mathrm{~V}$ choroid plexuses. Data are expressed as means \pm SEM

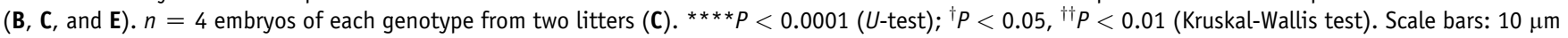
(A); $100 \mu \mathrm{m}$ (D). RPL, ribosomal protein L; RPS, ribosomal protein S.

\section{Statistics}

Biological replicates $(N)$ were defined as samples from distinct individuals analyzed either in the same experiment or across multiple experiments. Statistical analyses were performed using Prism software version 7 (GraphPad Software, La Jolla, CA) or R statistical software package (The $\mathrm{R}$ Foundation, https://www.r-project.org). Outliers were excluded using the ROUT method $(\mathrm{Q}=1 \%)$. Appropriate statistical tests were selected based on the distribution of data, homogeneity of variances, and sample size. The $F$ test or Bartlett test was used to assess homogeneity of variances between data sets. Parametric tests ( $t$-test, analysis of variance) were used only if data were normally distributed and variances were approximately equal. Otherwise, nonparametric alternatives were chosen. Data are presented as means \pm SEM. $P<0.05$ was considered significant.

\section{Results}

High Myc expression was detected in mouse embryonic day (E) 8.5 presumptive forebrain neuroepithelium before neural tube closure, and decreased expression in E10.5 neuroepithelium after the formation of the telencephalic vesicles
(Figure 1, A and B). Once down-regulated at E10.5, Myc expression in neural progenitors remained very low throughout embryonic cerebral cortical development (data not shown; see also Chau et $\mathrm{al}^{16}$ ).

To investigate the consequences of persistent Myc expression in the developing forebrain, StopFLMYC mice ${ }^{17}$ were crossed with nestin-Cre mice, ${ }^{18}$ in which Cre-mediated recombination is initiated at around E10.5. Although Myc was highly expressed throughout the cerebral cortex thereafter, cerebral cortical tissue showed no signs of tumorigenesis even into adulthood (data not shown). In contrast, although choroid plexus in Myc-OE mice appeared healthy at birth, some cells acquired nuclear atypia, including occasional prominent nucleoli, nuclear irregularity, and slight karyomegaly by postnatal day (P) 8 (data not shown). Ultimately, ectopic Myc expression in choroid plexus culminated in the development of choroid plexus tumors in adult mice, with complete penetrance (23 of 23 at 8 weeks of age) (Figure 1C).

Choroid plexus tumors showed striking ventricle-specific regionalization in the lateral and fourth ventricles, matching the typical presentation of tumors in the clinical setting. ${ }^{1}$ Notably, in all cases examined, tumors in the lateral ventricles regionalized to the posterior domain of the choroid plexus (Figure 1C), whereas tumors in the fourth ventricle 

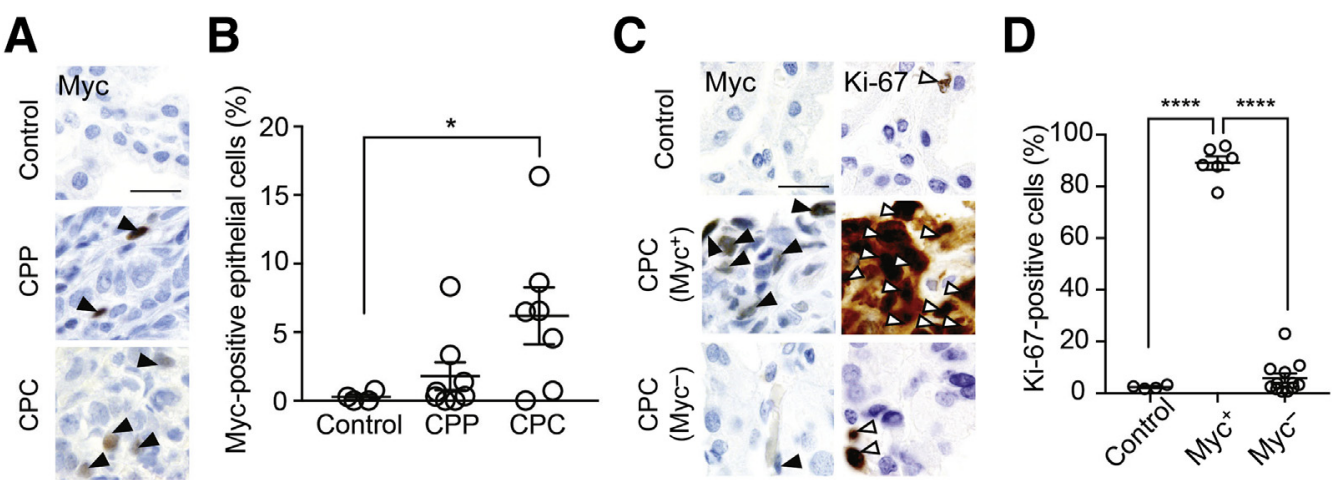

Figure 4 Human choroid plexus tumors display increased Myc expression correlating with increased proliferation. A: Myc staining in control choroid plexus (top), choroid plexus papilloma (CPP; middle), and choroid plexus carcinoma (CPC; bottom) from patients. Arrowheads indicate Myc-positive cells. B: Quantification of percentage of Myc-positive staining epithelial cells in control choroid plexus, CPP, and CPC samples. C: Representative images showing Myc and Ki-67 staining in control choroid plexus (top), CPC-expressing Myc (middle), and CPC not expressing Myc (bottom) from human patients. Black arrowheads indicate Myc-positive cells; white arrowheads indicate Ki-67-positive cells. D: Ki-67 levels in the Myc-expressing CPC sample are significantly higher than in either the Myc-negative CPC sample or the control samples. Each data point represents one field of view from a single sample. Data are expressed as means \pm SEM (B and $\mathbf{D}) .{ }^{*} P<0.05,{ }^{* * * * P}<0.0001$ (Welch corrected $t$-test). Scale bars $=20 \mu \mathrm{m}(\mathbf{A}$ and $\mathbf{C})$.

choroid plexus were found throughout the tissue (Figure 1C). No third ventricle tumors were observed.

Histologic analysis of six choroid plexus tumors from the lateral and fourth ventricles of three adult animals showed histology most consistent with CPC (World Health Organization grade $\mathrm{III}^{19,20}$ ), as all tumors met four of the five World Health Organization criteria for CPC: i) at least five mitoses per 10 high-power fields, ii) increased cellular density, iii) nuclear pleomorphism, iv) loss of papillary architecture, and v) necrosis (Table 1 and Figure 1D). The Ki-67 proliferation-labeling index for these CPCs ranged from $45 \%$ to $74 \%$ (Figure 1E). Additional immunohistochemical analyses revealed that all six CPCs were variably immunoreactive to both transthyretin and Kir7.1 (Table 1
A

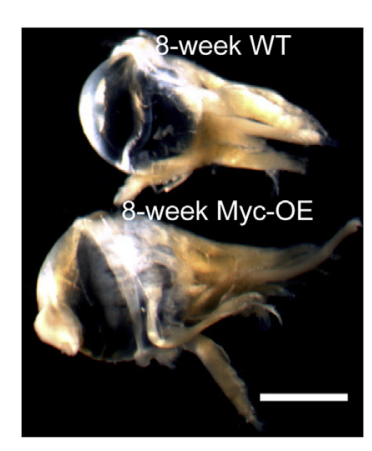

G

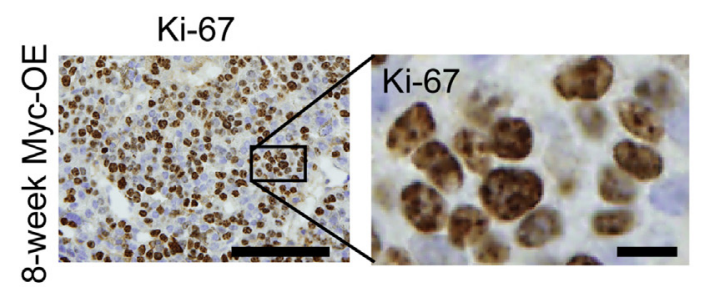

B

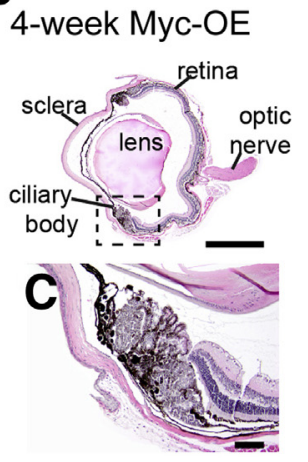

D

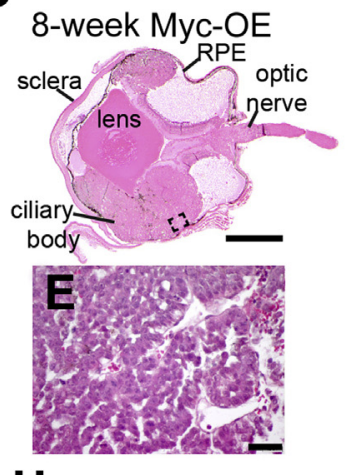

H

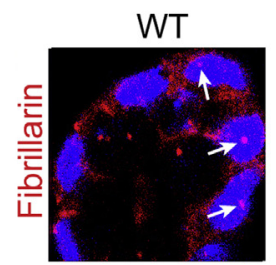

$\mathbf{F}$
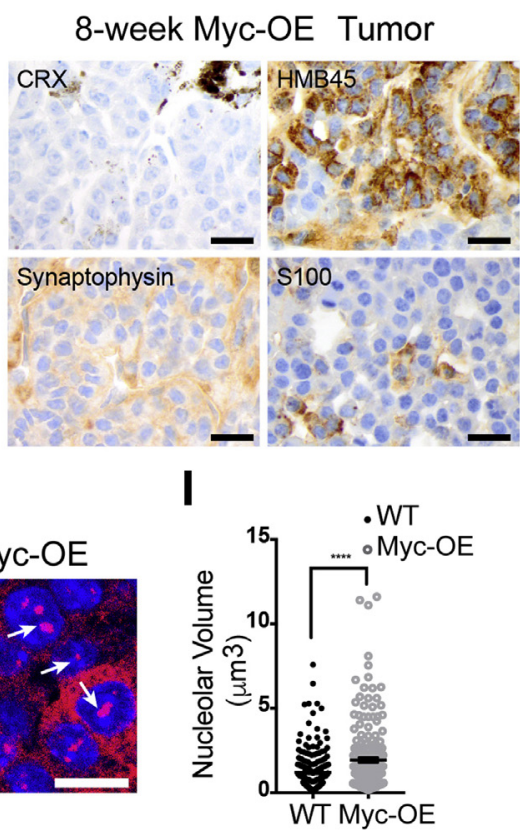

Figure 5 Persistent Myc expression drives tumorigenesis in the eye. A: Gross morphology shows an increase in eye size in the tumorigenic eye of an 8-week-old Myc-overexpressed (OE) mouse as compared to a wild-type (WT) littermate. B and C: Hematoxylin and eosin (H\&E) staining shows incipient tumors present in situ arising from the ciliary body of the eye at 4 weeks after persistent Myc expression. The boxed area in $\mathbf{B}$ is shown at higher magnification in $\mathbf{C}$. D and E: H\&E staining shows medulloepithelioma in 8-week-old Myc-0E mice. The boxed area in D is shown at higher magnification in E. F: Immunohistochemical analysis indicates that the tumor is neither retinoblastoma [absent cone-rod homeobox (CRX), variable synaptophysin], nor melanoma [variable positivity for human melanoma black (HMB)-45, low S100]. G: Ki-67 staining shows high proliferation in the ciliary body medulloepithelioma in Myc-0E mice. The boxed area in $\mathbf{G}$ is shown at high magnification in $\mathbf{H}$. $\mathbf{H}$ and I: Nucleolar volume was higher in the ciliary bodies of Myc-0E mice than in those of WT mice at 8 weeks, as indicated by fibrillarin staining. Arrows in $\mathbf{H}$ indicate fibrillarin-positive nucleoli. Data are expressed as means \pm SEM $(\mathbf{I})$. ${ }^{* * * * P}<0.0001($ Welch corrected $t$-test). Scale bars: $2 \mathrm{~mm}(\mathbf{A}) ; 1 \mathrm{~mm}(\mathbf{B}$ and $\mathbf{D}) ; 100 \mu \mathrm{m}(\mathbf{C}$ and $\mathbf{G}) ; 40 \mu \mathrm{m}(\mathbf{E}) ; 20 \mu \mathrm{m}(\mathbf{F}) ; 10 \mu \mathrm{m}$ (G, inset, and $\mathbf{H})$. RPE, retinal pigment epithelium. 

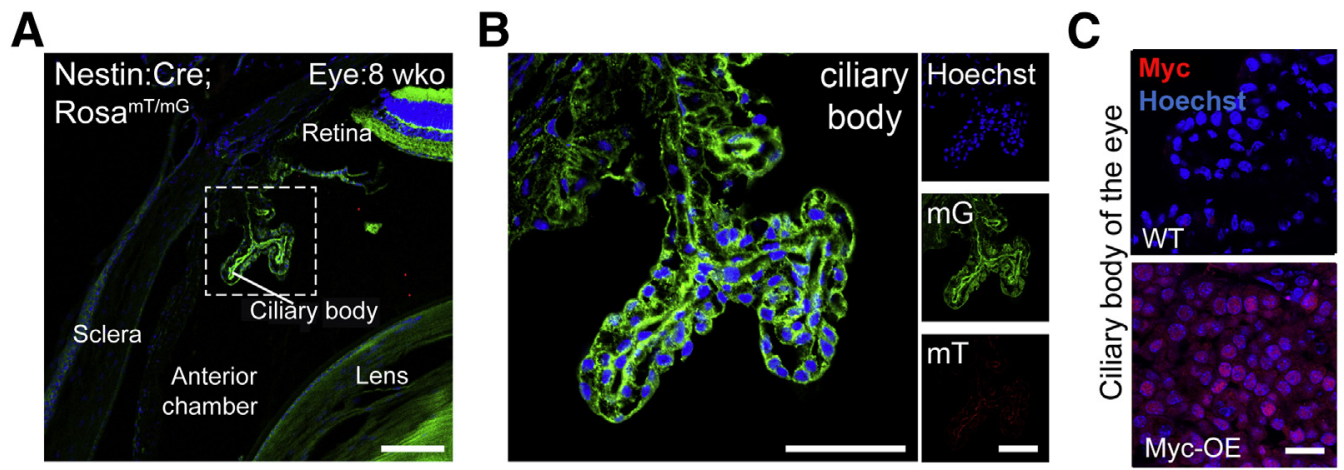

Figure 6 Cre recombination and Myc overexpression in the eye. A and B: Nestin-Cre recombination in the eye of an 8-week-old (wko) mouse, shown by red-to-green transition in the Rosa ${ }^{\mathrm{mTmG}}$ mouse strain. The boxed area in $\mathbf{A}$ is enlarged in $\mathbf{B}$ to show the ciliary body of the eye. C: Myc-positive stained nuclei in tumorigenic regions of ciliary body of the eye in Myc-overexpressed (OE) mice. Scale bars: $100 \mu \mathrm{m}$ (A); $50 \mu \mathrm{m}$ (B); $20 \mu \mathrm{m}$ (C). WT, wild-type.

and Figure 1F), confirming tumor origin from the choroid plexus. $^{21,22}$ Some CPCs demonstrated involvement of the ependymal layer, with minimal invasion of the brain parenchyma (data not shown). Loss of Trp53 expression was not detected in tumor versus control tissues (data not shown), indicating mechanisms other than those associated with Li-Fraumeni syndrome, in which CPCs are common. ${ }^{23}$ While healthy, unaffected choroid plexus cells are typically multiciliated, transformed cells were more likely to harbor a single primary cilium (Figure 1G), supporting a model in which multiciliated epithelia transition to monociliated epithelia with increased aggressiveness of disease. ${ }^{3,24}$

Choroid plexus epithelial cells differentiate from the roof plate and neuroectodermal lineage along the neural tube, ${ }^{25-27}$ but they are not commonly appreciated to be part of the nestin lineage. Nestin-Cre/Rosa ${ }^{\mathrm{mTmG}}$ reporter mice initially showed temporal and spatial Cre mosaicism with limited recombination (GFP-positive cells) in the choroid plexus of the lateral ventricles at birth (Figure 2A), and higher rates of recombination in the ventral regions of the fourth ventricle choroid plexus (Figure 2B). However, by $\mathrm{P} 8$, Cre recombination recognized by $\mathrm{Rosa}^{\mathrm{mTmG}}$ had occurred throughout each choroid plexus in each ventricle in the brain (Figure 2, C-H; data not shown). Therefore, the regionalized Myc expression and tumor development was unlikely to be due to inefficiency of Cre expression. Despite this nestin-Cre recombination, Myc expression was restricted to the posterior domain of the lateral ventricle choroid plexus and fourth ventricle choroid plexus (Figure 2, I and J). Although the anterior lateral ventricle and third ventricle choroid plexuses are induced separately, the exclusion of Myc in these regions agrees with a previously suggested similarity between them. ${ }^{28}$ Collectively, these data underscore the importance of patterned domains in the choroid plexus, ${ }^{29}$ and the selective vulnerability of certain epithelial cells in the neural lineage to tumorigenesis.

Unbridled Myc expression in choroid plexus tumors up-regulated the protein biosynthetic pathway. As increased ribosome biogenesis is associated with nucleolar hypertrophy, ${ }^{30}$ nucleolar volume provides a proxy for ribosome biogenesis. ${ }^{14,15}$ After visualization of nucleoli with fibrillarin (Figure 3A), three-dimensional reconstructions of individual nucleoli were performed in choroid plexus epithelial cells. Quantification of nucleolar volume revealed that Myc expression led to larger nucleoli (Figure 3B), indicative of increased ribosome biogenesis. Remarkably, select ribosomal subunit transcripts known to be Myc targets in other tissues ${ }^{31-33}$ were differentially expressed in choroid plexus tumors. For example, levels of Rps17 were decreased (Figure 3C), but those of Rps5, Rps12, Rpl11, and Rpl10a were increased in choroid plexus tumors (Figure 3C), suggesting the up-regulation of select ribosomal proteins as part of the choroid plexus cancer-translational machinery. These changes in ribosome biogenesis were accompanied by higher rates of protein synthesis in both lateral and fourth ventricle tumors (Figure 3, D and E). Taken together, our findings demonstrate that Myc-driven tumorigenesis in the choroid plexus recapitulates cellular transitions common to accelerated cancer growth in other tissues. ${ }^{34-37}$ The shared mechanisms may provide common ground for future treatments of these rare tumors.

In the human brain, Myc family members are expressed in fetal cerebral neural tissues and retina, but very little to no Myc family member expression is detected in choroid plexus. ${ }^{10}$ Because copy number gains in chromosome 8 , which contains the $M Y C$ locus, are associated with human choroid plexus tumors, ${ }^{4}$ a panel of human choroid plexus tumors (choroid plexus papilloma and CPC) were screened for Myc expression by immunohistochemistry (Table 2). Myc expression was increased in several cases of choroid plexus papilloma and CPC compared to normal controls (Figure 4, A and B). As the CPC cases showed greater variation in the percentage of $\mathrm{Myc}$ positive-stained epithelial cells, mitotic activity and proliferation rate were examined specifically in Myc-positive versus Myc-negative CPCs, and more Ki-67-positive cells were observed in Myc-positive tumors (Figure 4, C and D), with a significant correlation between Myc and Ki-67 levels [Pearson correlation coefficient $(r)=0.81, P<0.0001]$. These data 
support the conclusion that higher Myc expression is associated with higher proliferation rates in human choroid plexus carcinoma, as in other Myc-expressing tumor types.

Myc-OE mice also developed bilateral, malignant, nonteratoid CBME of the eye, with complete penetrance (Figure 5, A-E). Nestin-Cre/Rosa ${ }^{\mathrm{mTmG}}$ reporter mice showed full recombination (GFP-positive cells) in the eye, including the ciliary body (Figure 6, A and B), and Myc protein expression was high in ciliary body epithelial cells of Myc-OE mice (Figure 6C). Histologic analyses revealed a focally pigmented neoplasm composed of cells with karyomegaly, hyperchromatic irregular nuclei, frequent mitoses, and apoptotic figures. Tumor tissue organized in sheets and cords (particularly visible in areas in which the cellular density did not preclude architecture), adenoid arrangement, and occasionally formed lumens (Figure 5E). Tumor cells were moderately cohesive. All tumors originated in the ciliary body (best seen at 4 weeks, before the tumor was so large as to potentially confound origin) (Figure 5, B and C), and grew in between the retina and choroid, extending posteriorly in the optic nerve, where it invaded the lamina cribrosa. Retinal detachment was observed, with accumulation of serous material behind the retina. The choroid and the anterior chambers were not involved (Figure 5, B and D).

Immunohistochemical stains further supported the diagnosis of CBME. The tumor cells had focal, variable synaptophysin immunolabeling, and occasional cells were positive for keratin (CAM5.2) and S100 expression. The pigment-containing cells expressed HMB45; all tumor cells were negative for CRX, an antibody specific for retinal origin (Figure 5F; data not shown). The cytology, histologic architecture, and immunoprofile described in the preceding paragraph argues against melanoma. Given the primitive aspect and location, the rare childhood cancer retinoblastoma was excluded by demonstrating origin of tumor from ciliary body, histologic features incompatible with retinoblastoma, as well as immunohistochemical pattern, ${ }^{38}$ in particular only patchy synaptophysin (neuronal marker) and absent CRX (retinal/pineal lineage marker) expression (Figure 5F). Although tumors were pigmented, they were not uveal melanoma based primarily on tumor architecture. Cordlike growth patterns were present in the tumors, and this pattern would be unusual for melanoma (Figure 5E). Although HMB45 immunoexpression is seen in melanoma, consistent with the current literature on human CBME, ${ }^{39,40}$ tumors were focally immunopositive for HMB45 and, to a lesser degree, S100 (Figure 5F). Moreover, the presence of HMB45 expression with almost complete absence of S100 is more consistent with a pathologic diagnosis of CBME than with melanoma, which is $\mathrm{S} 100$ positive. Sebaceous and basal cell carcinoma and other epithelial tumors were also ruled out based on low levels of keratin (CAM5.2) expression in the tumorigenic domain of the eye (data not shown). Ki-67 staining demonstrated high proliferation rates in CBMEs in Myc-OE mice (Figure 5G). Quantification of nucleolar volume revealed that Myc expression led to larger nucleoli (Figure 5, H and I), indicative of increased ribosome biogenesis in these CBMEs, similar to the findings in the choroid plexus (Figure 3, A and B).

Tumorigenesis in Myc-OE mice was accompanied by hydrocephalus and behavioral manifestations of persistent clockwise or counterclockwise movements (whirling). No obvious tumors were observed around the eighth cranial nerve (data not shown), consistent with the nonplacodal origin of the vestibulocochlear ganglion. These data suggest that the vestibular defect was likely due to the onset of hydrocephalus and increasing intracranial pressure resulting from the choroid plexus tumors. Positron emission tomography imaging at 4 to 10 weeks did not reveal additional tumors in the bodies of the mice (Supplemental Figure S1; data not shown). Due to health considerations, mice were euthanized between 8 and 12 weeks of age. As such, the possibility of forthcoming tumorigenesis in other regions of the brain and/or body cannot be excluded.

\section{Discussion}

Here, we find that endogenous Myc is down-regulated in the forebrain neuroepithelium, and that prolonged expression of human Myc in the nestin lineage results in selective tumorigenesis in the choroid plexus and ciliary body of the eye, with complete penetrance. The rapid down-regulation of Myc expression after neural tube closure was unexpected, as E10.5 represents a stage of intense progenitor proliferation and the beginning of cerebral cortical neurogenesis. During the analogous developmental stage of the cerebellum, expression of other Myc family members (eg, $\mathrm{N}$-myc) are maintained during the expansion of cerebellar granule neurons. ${ }^{41}$

Longstanding models of disease pathogenesis in adults predict root causes in missteps of early development. An instructive example comes from Li-Fraumeni syndrome, in which inherited or de novo mutations during embryogenesis predispose individuals to later-onset cancers. ${ }^{5}$ Accordingly, although nestin-directed $\mathrm{Cre}$ recombination in choroid plexus begins during late embryogenesis, the consequences of persistent, high Myc expression manifests as tumors weeks later postnatally. Nestin is expressed in virtually all neural lineages; however, tumors are observed only in the posterior domain of the lateral ventricle choroid plexus, fourth ventricle choroid plexus, and ciliary body of the eye. Although the mechanisms regulating the temporal and cell-type specificity of nestin-Cre recombination in the choroid plexus remain to be tested, these findings underscore the importance of patterned domains in the choroid plexus, ${ }^{29}$ and the selective vulnerability of certain subtypes of epithelial cells to tumorigenesis.

Key features, including i) complete penetrance, ii) regionalization of tumor formation to the posterior domain of the lateral ventricle choroid plexus and fourth ventricle 
choroid plexus, and iii) developmental timeline consistent with clinical presentation of CPC primarily occurring in the first 5 years of life, ${ }^{42}$ distinguish this Myc-OE choroid plexus tumor model from other previously reported models of CPC. ${ }^{3,4,43}$ We show that Myc overexpression alone is sufficient to induce the development of CPC, and that other genetic modifications (eg, Tp53 deletion observed in Li-Fraumeni syndrome) are not required. Our findings elucidate new mechanisms for CPC formation, and are clinically salient, as recent reports suggest that up to $50 \%$ of CPC patients lack $T p 53$ deletion. ${ }^{44,45}$

In summary, our findings expose the vulnerability of epithelial cells in the nestin lineage to oncogenic transformation. Supplying Myc in this patterned context leads to the development of regionalized CPC that is accompanied by up-regulated ribosome biogenesis, protein synthesis, and hydrocephalus. Myc expression is also found in human CPC. To our knowledge, this Myc-OE mouse is the first model reported for CBME, and our extensive neuropathologic assessment demonstrates that this model faithfully recapitulates the defining features of CBME. Overall, this mouse overexpressing Myc in the nestin lineage provides new opportunities for investigating the molecular pathogenesis of these rare pediatric tumors.

\section{Acknowledgments}

We thank members of the Lehtinen Laboratory for helpful discussions; Sandro Santagata (Brigham and Women's Hospital, Boston, MA) for performing CRX staining and sharing reagents; and Hillary Mullan, Erin Snay $(\mathrm{BCH}$ Small Animal Imaging Laboratory, Boston, MA) and the Beth Israel Deaconess Medical Center Histology Core (Boston, MA) for technical assistance.

\section{Supplemental Data}

Supplemental material for this article can be found at https://doi.org/10.1016/j.ajpath.2018.02.009.

\section{References}

1. Safaee M, Oh MC, Bloch O, Sun MZ, Kaur G, Auguste KI, Tihan T, Parsa AT: Choroid plexus papillomas: advances in molecular biology and understanding of tumorigenesis. Neuro Oncol 2013, 15:255-267

2. Kaliki S, Shields CL, Eagle RC Jr, Vemuganti GK, Almeida A, Manjandavida FP, Mulay K, Honavar SG, Shields JA: Ciliary body medulloepithelioma: analysis of 41 cases. Ophthalmology 2013, 120: $2552-2559$

3. Li L, Grausam KB, Wang J, Lun MP, Ohli J, Lidov HG, Calicchio ML, Zeng E, Salisbury JL, Wechsler-Reya RJ, Lehtinen MK, Schüller U, Zhao H: Sonic hedgehog promotes proliferation of Notch-dependent monociliated choroid plexus tumour cells. Nat Cell Biol 2016, 18:418-430

4. Tong Y, Merino D, Nimmervoll B, Gupta K, Wang YD, Finkelstein D, Dalton J, Ellison DW, Ma X, Zhang J, Malkin D, Gilbertson RJ: Cross- species genomics identifies TAF12, NFYC, and RAD54L as choroid plexus carcinoma oncogenes. Cancer Cell 2015, 27:712-727

5. Valdez JM, Nichols KE, Kesserwan C: Li-Fraumeni syndrome: a paradigm for the understanding of hereditary cancer predisposition. $\mathrm{Br}$ J Haematol 2017, 176:539-552

6. Momota H, Shih AH, Edgar MA, Holland EC: c-Myc and beta-catenin cooperate with loss of p53 to generate multiple members of the primitive neuroectodermal tumor family in mice. Oncogene 2008, 27: 4392-4401

7. Pomeroy SL, Tamayo P, Gaasenbeek M, Sturla LM, Angelo M, McLaughlin ME, Kim JY, Goumnerova LC, Black PM, Lau C, Allen JC, Zagzag D, Olson JM, Curran T, Wetmore C, Biegel JA, Poggio T, Mukherjee S, Rifkin R, Califano A, Stolovitzky G, Louis DN, Mesirov JP, Lander ES, Golub TR: Prediction of central nervous system embryonal tumour outcome based on gene expression. Nature 2002, 415:436-442

8. Northcott PA, Buchhalter I, Morrissy AS, Hovestadt V, Weischenfeldt J, Ehrenberger T, et al: The whole-genome landscape of medulloblastoma subtypes. Nature 2017, 547:311-317

9. Archer TC, Mahoney EL, Pomeroy SL: Medulloblastoma: molecular classification-based personal therapeutics. Neurotherapeutics 2017, 14: $265-273$

10. Hirvonen H, Makela TP, Sandberg M, Kalimo H, Vuorio E, Alitalo K: Expression of the myc proto-oncogenes in developing human fetal brain. Oncogene 1990, 5:1787-1797

11. Swartling FJ, Savov V, Persson AI, Chen J, Hackett CS, Northcott PA, Grimmer MR, Lau J, Chesler L, Perry A, Phillips JJ, Taylor MD, Weiss WA: Distinct neural stem cell populations give rise to disparate brain tumors in response to N-MYC. Cancer Cell 2012, 21:601-613

12. Streit A: Early development of the cranial sensory nervous system: from a common field to individual placodes. Dev Biol 2004, 276:1-15

13. Matsushima D, Heavner W, Pevny LH: Combinatorial regulation of optic cup progenitor cell fate by SOX2 and PAX6. Development 2011, 138:443-454

14. Baker NE: Developmental regulation of nucleolus size during drosophila eye differentiation. PLoS One 2013, 8:e58266

15. Sanchez CG, Teixeira FK, Czech B, Preall JB, Zamparini AL, Seifert JR, Malone CD, Hannon GJ, Lehmann R: Regulation of ribosome biogenesis and protein synthesis controls germline stem cell differentiation. Cell Stem Cell 2016, 18:276-290

16. Chau KF, Shannon ML, Fame RM, Fonseca E, Mullan H, Johnson MB, Sendamarai AK, Springel MW, Laurent B, Lehtinen MK: Downregulation of ribosome biogenesis during early forebrain development. eLife 2018, 7:e36998

17. Calado D, Sasaki Y, Godinho SA, Pellerin A, Köchert K Sleckman BP, de Alborán I, Janz M, Rodig S, Rajewsky K: The cellcycle regulator c-Myc is essential for the formation and maintenance of germinal centers. Nat Immunol 2012, 13:1092-1100

18. Tronche F, Kellendonk C, Kretz O, Gass P, Anlag K, Orban PC, Bock R, Klein R, Schütz G: Disruption of the glucocorticoid receptor gene in the nervous system results in reduced anxiety. Nat Genet 1999, 23:99-103

19. Louis DN, Ohgaki H, Wiestler OD, Cavenee WK, Ellison DW, FigarellaBranger D, Perry A, Reifenberger G, von Deimling A: Choroid plexus tumors. Edited by Louis DN, Ohgaki H, Wiestler OD, Cavenee WK. In WHO Classification of Tumours of the Central Nervous System. Geneva, Switzerland: World Health Organization, 2016. pp. 124-129

20. Jeibmann A, Hasselblatt M, Gerss J, Wrede B, Egensperger R, Beschorner R, Hans VH, Rickert CH, Wolff JE, Paulus W: Prognostic implications of atypical histologic features in choroid plexus papilloma. J Neuropathol Exp Neurol 2006, 65:1069-1073

21. Schittenhelm J, Roser F, Tatagiba M, Beschorner R: Diagnostic value of EAAT-1 and Kir7.1 for distinguishing endolymphatic sac tumors from choroid plexus tumors. Am J Clin Pathol 2012, 138:85-89

22. Mishra A, Srivastava C, Singh SK, Chandra A, Ojha BK: Choroid plexus carcinoma: case report and review of literature. J Pediatr Neurosci 2012, 7:71-73 
23. Mai PL, Best AF, Peters JA, DeCastro RM, Khincha PP, Loud JT, Bremer RC, Rosenberg PS, Savage SA: Risks of first and subsequent cancers among TP53 mutation carriers in the National Cancer Institute Li-Fraumeni syndrome cohort. Cancer 2016, 122:3673-3681

24. Abedalthagafi MS, Wu MP, Merrill PH, Du Z, Woo T, Sheu S-HH, Hurwitz S, Ligon KL, Santagata S: Decreased FOXJ1 expression and its ciliogenesis programme in aggressive ependymoma and choroid plexus tumours. J Pathol 2016, 238:584-597

25. Lun MP, Monuki ES, Lehtinen MK: Development and functions of the choroid plexus-cerebrospinal fluid system. Nat Rev Neurosci 2015, 16 : 445-457

26. Hunter NL, Dymecki SM: Molecularly and temporally separable lineages form the hindbrain roof plate and contribute differentially to the choroid plexus. Development 2007, 134:3449-3460

27. Awatramani R, Soriano P, Rodriguez C, Mai JJ, Dymecki SM: Cryptic boundaries in roof plate and choroid plexus identified by intersectional gene activation. Nat Genet 2003, 35:70-75

28. Currle DS, Cheng X, Hsu CM, Monuki ES: Direct and indirect roles of CNS dorsal midline cells in choroid plexus epithelia formation. Development 2005, 132:3549-3559

29. Lun MP, Johnson MB, Broadbelt KG, Watanabe M, Kang YJ, Chau KF, Springel MW, Malesz A, Sousa AM, Pletikos M, Adelita T, Adelita T, Calicchio ML, Zhang Y, Holtzman MJ, Lidov HG, Sestan N, Steen H, Monuki ES, Lehtinen MK: Spatially heterogeneous choroid plexus transcriptomes encode positional identity and contribute to regional CSF production. J Neurosci 2015, 35:4903-4916

30. Silvera D, Formenti SC, Schneider RJ: Translational control in cancer. Nat Rev Cancer 2010, 10:254-266

31. Hunecke D, Spanel R, Langer F, Nam SW, Borlak J: MYC-regulated genes involved in liver cell dysplasia identified in a transgenic model of liver cancer. J Pathol 2012, 228:520-533

32. Wang X, Ren Y, Wang Z, Xiong X, Han S, Pan W, Chen H, Zhou L, Zhou C, Yuan Q, Yang M: Down-regulation of 5S rRNA by miR-150 and miR-383 enhances c-Myc-rpL11 interaction and inhibits proliferation of esophageal squamous carcinoma cells. FEBS Lett 2015, 589: 3989-3997

33. Kidder BL, Yang J, Palmer S: Stat3 and c-Myc genome-wide promoter occupancy in embryonic stem cells. PLoS One 2008, 3:e3932

34. Barna M, Pusic A, Zollo O, Costa M, Kondrashov N, Rego E, Rao PH, Ruggero D: Suppression of Myc oncogenic activity by ribosomal protein haploinsufficiency. Nature 2008, 456:971-975
35. Hsieh AC, Liu Y, Edlind MP, Ingolia NT, Janes MR, Sher A, Shi EY, Stumpf CR, Christensen C, Bonham MJ, Wang S, Ren P, Martin M, Jessen K, Feldman ME, Weissman JS, Shokat KM, Rommel C, Ruggero D: The translational landscape of mTOR signalling steers cancer initiation and metastasis. Nature 2012, 485:55-61

36. Pourdehnad M, Truitt ML, Siddiqi IN, Ducker GS, Shokat KM, Ruggero D: Myc and mTOR converge on a common node in protein synthesis control that confers synthetic lethality in Myc-driven cancers. Proc Natl Acad Sci U S A 2013, 110:11988-11993

37. van Riggelen J, Yetil A, Felsher DW: MYC as a regulator of ribosome biogenesis and protein synthesis. Nat Rev Cancer 2010, 10:301-309

38. Santagata S, Maire CL, Idbaih A, Geffers L, Correll M, Holton K, Quackenbush J, Ligon KL: CRX is a diagnostic marker of retinal and pineal lineage tumors. PLoS One 2009, 4:e7932

39. Steuhl KP, Rohrbach JM, Knorr M, Thiel HJ: Significance, specificity, and ultrastructural localization of HMB-45 antigen in pigmented ocular tumors. Ophthalmology 1993, 100:208-215

40. Al-Salam S, Algawi K, Alashari M: Malignant non-teratoid medulloepithelioma of ciliary body with retinoblastic differentiation: a case report and review of literature. Neuropathology 2008, 28:551-556

41. Ruppert C, Goldowitz D, Wille W: Proto-oncogene c-myc is expressed in cerebellar neurons at different developmental stages. EMBO J 1986, 5:1897-1901

42. Dudley RW, Torok MR, Gallegos D, Liu AK, Handler MH, Hankinson TC: Pediatric choroid plexus tumors: epidemiology, treatments, and outcome analysis on 202 children from the SEER database. J Neurooncol 2015, 121:201-207

43. Dang L, Fan X, Chaudhry A, Wang M, Gaiano N, Eberhart CG: Notch3 signaling initiates choroid plexus tumor formation. Oncogene 2006, 25:487-491

44. Gozali AE, Britt B, Shane L, Gonzalez I, Gilles F, McComb JG, Krieger MD, Lavey RS, Shlien A, Villablanca JG, Erdreich-Epstein A, Dhall G, Jubran R, Tabori U, Malkin D, Finlay JL: Choroid plexus tumors; management, outcome, and association with the Li-Fraumeni syndrome: the Children's Hospital Los Angeles (CHLA) experience, 1991-2010. Pediatr Blood Cancer 2012, 58:905-909

45. Tabori U, Shlien A, Baskin B, Levitt S, Ray P, Alon N, Hawkins C, Bouffet E, Pienkowska M, Lafay-Cousin L, Gozali A, Zhukova N, Shane L, Gonzalez I, Finlay J, Malkin D: TP53 alterations determine clinical subgroups and survival of patients with choroid plexus tumors. J Clin Oncol 2010, 28:1995-2001 